\section{References}

1. Cammack Pl, Edie RN, Edmunds LH Jr. Bar calcification of the mitral annulus: a risk factor in mitral valve operations. J Thorac Cardiovasc Surg. 1987;94: 399-404.

2. Grossi EA, Galloway AC, Steinberg BM, Leboutillier M III, Delianides J, Baumann FG, et al. Severe calcification does not affect long-term outcome of mitral valve repair. Ann Thorac Surg. 1994;58:685-8.
3. Carpentier AF, Pellerin M, Fuzellier JF, Relland JY. Extensive calcification of the mitral valve annulus: pathology and surgical management. J Thorac Cardiovasc Surg. 1996;111:718-30.

4. David TE, Feindel CM, Armstrong S, Sun Z. Reconstruction of the mitral annulus: a ten-year experience. J Thorac Cardiovasc Surg. 1995;110:1323-32.

5. Feindel CM, Tufail Z, David TE, Ivanov J, Armstrong S. Mitral valve surgery in patients with extensive calcification of the mitral annulus. $J$ Thorac Cardiovasc Surg. 2003;126:777-82.

\title{
Use of a polytetrafluoroethylene graft to prevent recurrence of saphenous vein graft aneurysm after coronary artery bypass grafting
}

\author{
Syed T. Hussain, MD, Nicholas G. Smedira, MD, and Eric E. Roselli, MD, Cleveland, Ohio
}

Dilatation of vein grafts occurs in $14 \%$ of patients within 14 years after coronary artery bypass grafting (CABG), but is rarely of concern. ${ }^{1}$ Saphenous vein graft (SVG) aneurysm (SVGA), however, is a potentially fatal complication. ${ }^{2,3}$ In a recent retrospective analysis, only 16 patients underwent surgical repair of SVGAs during a 30-year interval in which 28,603 patients underwent CABG. ${ }^{4}$ Recurrence of SVGA after reoperation is unknown. Theoretically, the risk remains, because the conditions for development of this complication are unchanged. We describe a novel technique with a polytetrafluoroethylene graft to encapsulate the new vein graft and avoid late aneurysmal degeneration.

\section{CLINICAL SUMMARY}

A 66-year-old man underwent CABG in 1993, with separate SVGs to the obtuse marginal artery $(\mathrm{OM})$ and the posterior descending artery (PDA) and a left internal thoracic artery graft to the left anterior descending coronary artery. He had a history of bilateral popliteal artery aneurysms that were stented. Twelve years after this operation, during a workup for dizziness, he had a coronary angiogram that showed aneurysmal dilatation of his vein grafts. He was started on warfarin, and no other intervention was performed. He came to us 5 years later with new, recurring substernal chest pain. A repeated coronary angiogram showed a dilated yet patent vein graft to the OM. The right graft could not be engaged during the angiogram. Computed

From the Department of Thoracic and Cardiovascular Surgery, Heart and Vascular Institute, Cleveland Clinic, Cleveland, Ohio.

Disclosures: Authors have nothing to disclose with regard to commercial support.

Received for publication Jan 31, 2013; accepted for publication Feb 13, 2013; available ahead of print March 8, 2013.

Address for reprints: Eric E. Roselli, MD, Cleveland Clinic, Department of Thoracic and Cardiovascular Surgery, 9500 Euclid Ave, Desk J4-1, Cleveland, OH 44195 (E-mail: roselle@ccf.org).

J Thorac Cardiovasc Surg 2013;145:1674-5

$0022-5223 / \$ 36.00$

Copyright (c) 2013 by The American Association for Thoracic Surgery

http://dx.doi.org/10.1016/j.jtcvs.2013.02.033 tomography of the chest showed diffuse aneurysms of both the OM and PDA vein grafts, with maximum diameters of 3.1 and $5 \mathrm{~cm}$, respectively (Figure 1).
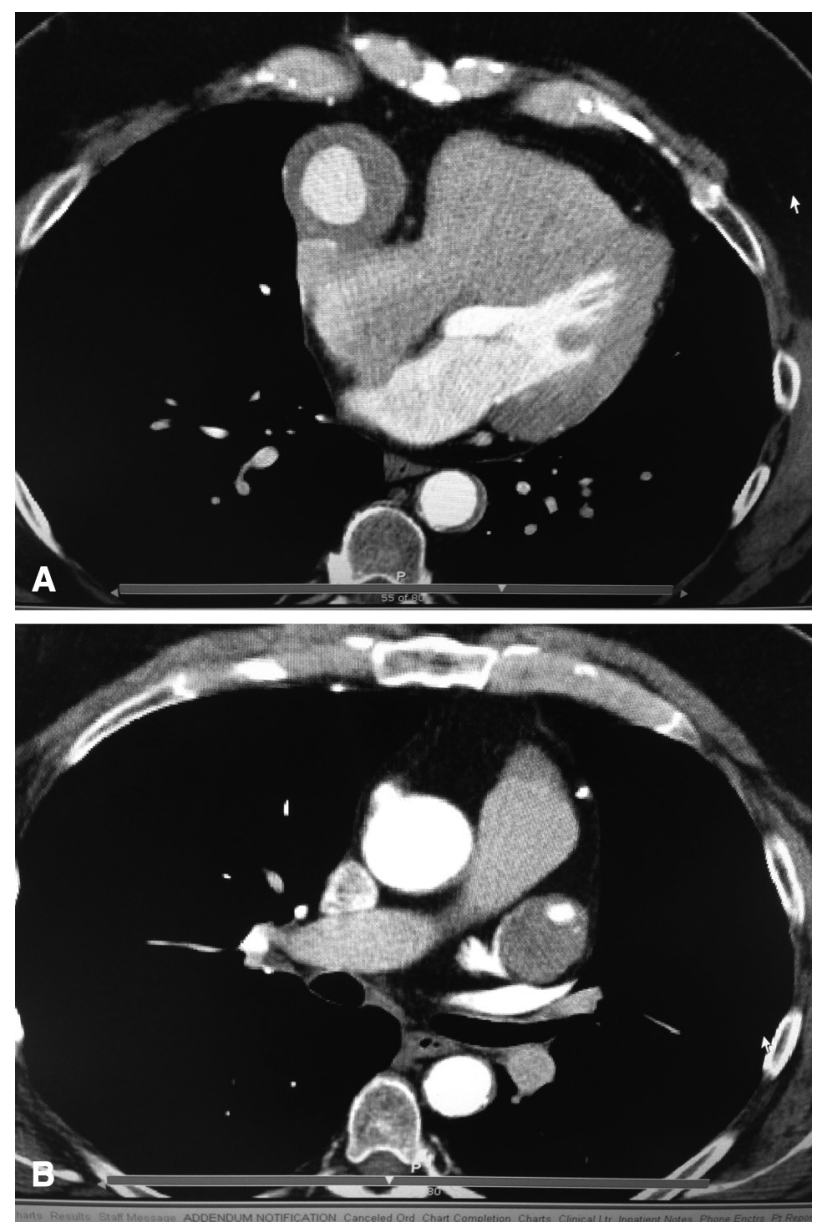

FIGURE 1. Preoperative computed tomographic scan showing large pseudoaneurysm of saphenous vein graft to the right coronary artery (A) and to the obtuse marginal artery (B). 

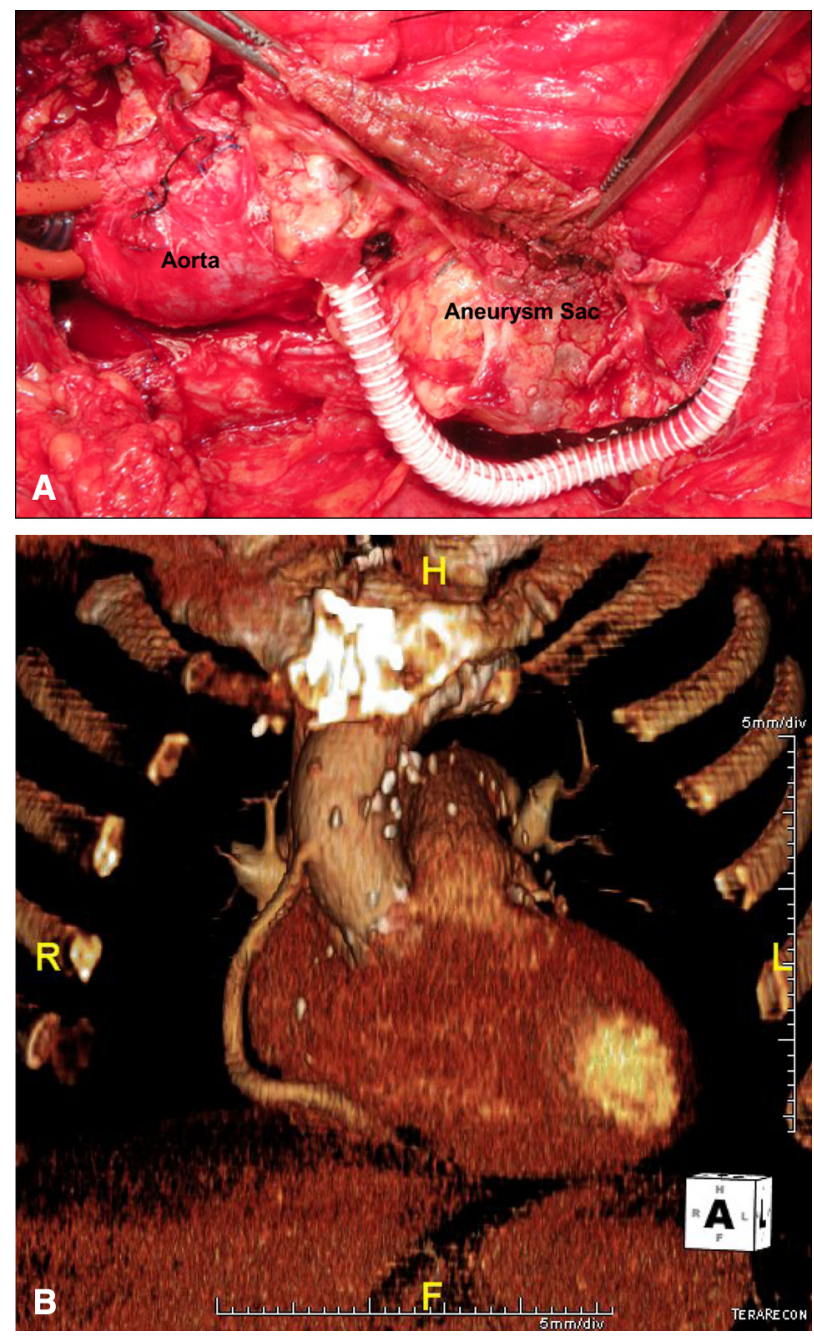

FIGURE 2. A, Intraoperative photograph demonstrating the polytetrafluoroethylene graft sleeve over the aortocoronary bypass graft. B, Reconstructed computed tomographic angiogram showing the patent and normal aortocoronary bypass graft.

Reoperative median sternotomy was performed. After adhesiolysis, cannulation was performed through the ascending aorta and superior vena cava with a 3-stage cannula to avoid manipulation of the SVGAs. After cardiac arrest, the SVGA to the PDA was transected proximally, the aneurysm was opened, and distal anastomosis of the new SVG to the PDA was performed. A 6-mm ringed polytetrafluoroethylene graft was placed as a sleeve over the new SVG, and the proximal anastomosis was completed (Figure 2, A). The OM graft aneurysm was resected, and a free right internal thoracic artery graft was used as a replacement. The patient had an uneventful recovery. Eighteen months after surgery, computed tomography showed a patent and normal vein graft with no aneurysmal degeneration (Figure 2, B).

\section{DISCUSSION}

SVGAs are rare, ${ }^{1,4,5}$ but their prevalence is underestimated because many patients are symptom free. Etiology is incompletely understood, and atherosclerosis, surgical technique, and infection have been implicated. ${ }^{4,5}$ The vicinity of the venous valves may be intrinsically weak because of lack of circular muscle, and veins may also be weakened at branching sites or in areas damaged by initial surgical procedures. ${ }^{4,5}$ There may also be a possible association with connective tissue disorders, as our patient also had bilateral popliteal aneurysms and later had SVGAs develop.

SVGA usually presents with chest pain, ${ }^{3,4}$ but it may also present with rupture, compression of surrounding structures, fistula formation, or myocardial infarction. ${ }^{1,4,5}$ The triad of chest pain, mediastinal mass, and previous CABG should raise concern about the diagnosis. Suspected SVGA should be evaluated with computed tomography or magnetic resonance imaging of the chest and coronary angiography to delineate pathoanatomy and determine patency or other coronary stenoses.

Surgical resection of the aneurysm and revascularization has been the most common strategy used. Percutaneous interventions have been reported more recently, with $16 \%$ of cases treated by these methods. ${ }^{5}$

To avoid later aneurysmal degeneration, we covered our new vein graft with the polytetrafluoroethylene graft material and used the internal thoracic artery to replace the circumflex graft. This technique, which has not been described for managing SVGA, has proved to be stable, and grafts are patent at 18 months of follow-up. Because this patient population may be more vulnerable to aneurysmal degeneration of the SVG, the use of a polytetrafluoroethylene graft to encapsulate the SVG should be considered during these complex reoperations.

\section{References}

1. Memon AQ, Huang RI, Marcus F, Xavier L, Alpert J. Saphenous vein graft aneurysm: case report and review. Cardiol Rev. 2003;11:26-34.

2. Riahi M, Vasu CM, Tomatis LA, Schlosser RJ, Zimmerman G. Aneurysm of saphenous vein bypass graft to coronary artery. J Thorac Cardiovasc Surg. 1975;70:358-9.

3. Nölke L, McGovern E, Wood AE. Saphenous vein graft aneurysms; the true, false and ugly! Interact Cardiovasc Thorac Surg. 2004;3:631-3.

4. Sareyyupoglu B, Schaff HV, Ucar I, Sundt TM 3rd, Dearani JA, Park SJ. Surgical treatment of saphenous vein graft aneurysms after coronary artery revascularization. Ann Thorac Surg. 2009;88:1801-5.

5. Ramirez FD, Hibbert B, Simard T, Pourdjabbar A, Wilson KR, Hibbert R, et al. Natural history and management of aortocoronary saphenous vein graft aneurysms: a systematic review of published cases. Circulation. 2012;126: 2248-56. 